\title{
Balloon atrial septostomy in complete transposition of great arteries in infancy
}

\author{
A. W. Venables \\ From Royal Children's Hospital, Melbourne, Australia
}

\begin{abstract}
The results of 26 completed balloon atrial septostomies in complete arterial transposition in infancy are described, and complications discussed. Of 7 deaths following this procedure, 3 were clearly or probably related to it or to its failure to produce an adequate septal defect, while 4 were unrelated. Atrial perforations occurred on 4 occasions.

Necropsy information regarding the defects produced by the procedure is given. Anatomical features of the fossa ovalis appear to determine the size of the defect created. The effect of the prosedure is illustrated by photographs of representative necropsy specimens. Apparently adequate initial defects do not guarantee satisfactory long-term palliation, and 4 of II infants followed for more than 6 months after effective initial palliation have required surgical procedures to provide more adequate atrial mixing of blood. Despite this, the procedure appears to offer considerable advantage over initial surgical procedures to create atrial defects.
\end{abstract}

The value of palliative procedures in complete arterial transposition is indisputable. Most commonly, atrial septal defects arz created in order to increase effective pulmonary flow. Since 1966 the balloon catheter technique of atrial septostomy introduced by Rashkind (Rashkind and Miller, I966) has come widely into use, displacing the surgical procedures previously employed to create atrial septal defects (Plauth et al., 1968; Venables, 1966). Though there is no doubt of the value of this procedure in obtaining palliation in many cases (Watson and Rashkind, 1967), there are few detailed reports of series indicating limitations of technique and follow-up progress, and permitting assessment of its true role in treatment of complete transposition in infancy (Rashkind and Miller, 1968; Venables, 1968).

This paper presents information regarding 26 infants in whom balloon atrial septostomy was completed as initial palliative treatment for complete transposition. The results are related to previous and current surgical experience in the same Unit (Venables, 1966), and problems are discussed. Information is given about the necropsy findings in those infants who died early, either as a result of technical failure or unrelated problems.

Received 13 June 1969.

\section{Subjects and methods}

From 1960 to mid-May 1969, 123 cases of transposition of the great arteries in infancy were diagnosed in the Cardiac Unit of the Royal Children's Hospital, Melbourne. These cases include 53 infants previously discussed (Venables, 1966). Palliative procedures to create atrial septal defects were performed in 88 infants, with 59 survivors who obtained effective immediate palliation. Defects were made surgically in 62 , while balloon septostomy was completed in 26 infants. Balloon septostomy has been performed since late 1966 in preference to initial surgical procedures, provided balloon catheters were available.

Balloon septostomy was performed after the diagnosis of complete transposition of the great arteries had been made by selective angiocardiography from right ventricle and left atrium or left ventricle. Pressure and oxygen saturation measurements were not always possible when the procedures were performed as emergency measures. Information about the response of these parameters to septostomy is therefore not available in all cases. Initially U.S. Catheter Corporation catheters were used, but from early in 1968 the Edwards Company balloon catheter was employed routinely (Venables, I968).

Age at the time of balloon septostomy ranged from 6 hours to 7 weeks. Weight ranged from $2 \cdot 16$ kg. to $4.80 \mathrm{~kg}$., with a mean weight of $3.38 \mathrm{~kg}$. Eight infants weighed less than $3 \mathrm{~kg}$. The degree of hypoxia and of consequent metabolic acidosis varied considerably. Six infants presented with $p \mathrm{H}$ values in capillary (heel-prick) blood of $7 \cdot 15$ 
or less, the lowest $p H$ recorded being 6.95. Acidosis was treated with intravenous sodium bicarbonate in appropriate dosage while preparations were being made for cardiac catheterization. Further bicarbonate was not ordinarily necessary after septostomy, the $\mathrm{pH}$ and base excess returning to normal levels and stabilizing there (Fig. I).

Ventricular septal defects of varying size were detected in ro of the infants in whom balloon septostomy was completed. Persistence of the ductus arteriosus was shown angiocardiographically in 16 instances. One infant with ventricular septal defect required pulmonary artery banding because of the development of cardiac failure after septostomy, and one infant died of heart failure due to persistence of a large ductus. In one infant included in the series, the attempt at septostomy showed the presence of an atrial septal defect through which a completely filled balloon passed readily without evidence of preliminary splitting of the fossa ovalis.

The outcome of the procedures is shown in Table r. Balloon septostomy was contemplated but abandoned in 5 of the infants operated on in 1967-1968. The reasons for this are shown in Table 2. On two occasions accidental perforation of the atrial wall occurred before septostomy was attempted. The procedure was abandoned and the baby treated by immediate thoracotomy, repair of the perforation, and a Blalock-Hanlon procedure. These infants have been transferred to the surgical group (Table I). One survived, but the other died of complications of the surgical procedure.

The factors responsible for early death in the first few days after completed balloon septostomy are set out in Table 3. Two deaths clearly represent technical failures. They were due to tricuspid

FIG. I pH and base excess levels before and after balloon septostomy in an infant with complete arterial transposition.
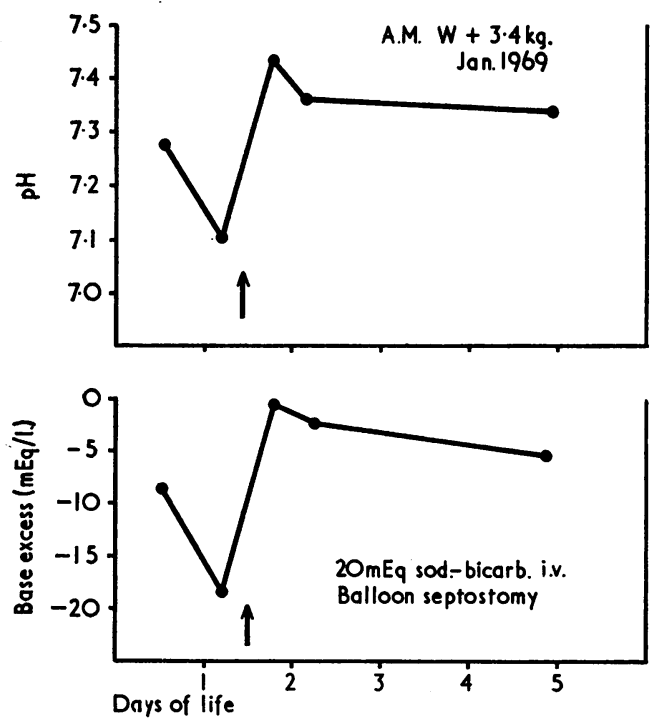

TABLE I Initial palliative procedures

\begin{tabular}{llll}
\hline & $\begin{array}{l}\text { No. of } \\
\text { cases }\end{array}$ & $\begin{array}{l}\text { Early } \\
\text { deaths }\end{array}$ & $\begin{array}{l}\text { Unrelated } \\
\text { late deaths }\end{array}$ \\
\hline Surgical atrial septal defects, 1960-68 & 62 & $22^{\star}$ & 10 \\
Surgical defects, 1967-68 & $13 \dagger$ & 2 & 1 \\
Balloon atrial septostomy (completed), & 26 & 7 & 2 \\
$\quad$ I966-69 & & &
\end{tabular}

* Includes some early failures of surgical procedures to create adequate defects.

† Includes 2 after abandonment of balloon procedure because of atrial perforation.

TABLE 2 Balloon septostomy contemplated but abandoned

\begin{tabular}{ll}
\hline & $\begin{array}{l}\text { No. of } \\
\text { cases }\end{array}$ \\
\hline $\begin{array}{ll}\text { Failure to introduce balloon into vein } \\
\text { Atrial perforation recognized, procedure } \\
\text { abandoned }\end{array}$ & 2 \\
\begin{tabular}{l} 
Manipulative difficulty \\
\hline
\end{tabular} & I \\
\hline
\end{tabular}

TABLE 3 Balloon atrial septostomy

\begin{tabular}{ll}
\hline & $\begin{array}{l}\text { No. of } \\
\text { cases }\end{array}$ \\
\hline Procedures completed & 26 \\
Early deaths & 7 \\
$\quad$ Tricuspid valve laceration & I \\
Failure to split fossa ovalis & I \\
Circulatory failure & I \\
Diffuse pulmonary haemorrhage, atrial & I \\
perforation & Ieonatal septicaemia \\
Cardiac failure from persistent ductus & I \\
Anoxic organ damage & I \\
\hline
\end{tabular}

TABLE 4 Initial balloon atrial septostomy (completed) Survivor follow-up

No. of

cases

Procedure performed before November 1968

Total survivors

II

Further procedure necessary

ate deaths

Infection

Sagittal sinus thrombosis $\}$

Current survivors

Procedure performed since November 1969

Total survivors

Late deaths 
valve laceration and to an inadequate defect. The death from circulatory failure appeared to be related at least partly to the presence of a greater degree of acidosis than appreciated. The remaining 4 deaths were due to unrelated problems, though the baby who was moribund from diffuse pulmonary haemorrhage when catheterization was begun was found at necropsy to have previously unrecognized atrial perforation and haemopericardium. Necropsies were performed after 6 of the 7 early deaths.

Follow-up data are given in Table 4. Of II survivors with satisfactory initial palliation followed for more than 6 months, 4 have required further surgical palliation at ages of from 5 to 7 months. All had Blalock-Hanlon procedures, though in one a further balloon procedure was first performed without satisfactory response. The 2 late deaths occurred after secondary surgical procedures, but were unrelated to surgery. These deaths were due to presumed sagittal sinus thrombosis and to severe infection. Necropsy was not performed in either case. The infants who have survived balloon septostomy since November 1968 are currently all in satisfactory condition. No information is available about the ultimate size of the defects in these infants with transposition. However, 2 infants from a small group with total anomalous pulmonary venous drainage also subjected to balloon septostomy in the same unit have now had operation at approximately 15 months of age. The defects produced by previous septostomy were then both approximately $1.5 \mathrm{~cm}$. in diameter.

\section{Discussion}

The material presented confirms that balloon atrial septostomy provides an acceptable technique for immediate palliation of infants with complete arterial transposition needing improvement in effective pulmonary flow. There were 3 deaths after septostomy to which the procedure appeared definitely or probably contributory. An additional death followed atrial perforation complicating introduction of a balloon catheter into the heart without actually performing septostomy. This was of purely surgical nature but, even when this is taken into consideration, the mortality related to the procedure compares favourably not only with over-all but with recent surgical experience in the same unit. Further, palliation has quite evidently been available to small infants and to very acidotic infants in whom an operation would have been unlikely to succeed (Rashkind and Miller, I968; Venables, I968).

Early deaths from unrelated causes, and late deaths from such causes as infection and cerebrovascular accidents, occurred as in other studies of infants with complete transposition.

It is important to consider the long-range effectiveness of palliation and the problem of the detection of inadequate atrial defects. In this series, 4 of II infants observed for more than 6 months since septostomy have required further procedures to provide a more adequate atrial septal defect. The others, including 2 infants observed for 32 and 21 months, respectively, remain satisfactory. Rashkind (Rashkind and Miller, 1968) reported 3 repeat septostomies between $I \frac{1}{2}$ and 5 months after the initial procedure, further study being prompted by 'the development of cardiomegaly plus some increase in cyanosis'.

The degree of cyanosis after successful palliation has varied in the present series as after successful Blalock-Hanlon procedures (Venables, 1966). The patients who were considered to require enlargement of their atrial defects were considerably cyanosed. Their condition had become generally unsatisfactory with irritability, poor feeding, and acidosis. In one case inadequate atrial shunts and a high left atrial pressure were shown at a further catheterization procedure. This study was aimed mainly at measuring pulmonary artery pressure and flow in reference to possible pulmonary artery banding because of an associated large ventricular septal defect. Unfortunately, no attempt was made to assess the actual defect size by use of a balloon catheter. When, however, another child was recatheterized recently at 4 months of age because of some increase in cyanosis associated with consistent mild acidosis, with $p \mathrm{H}$ readings of about $7 \cdot 30$, a balloon catheter passed freely through the atrial defect when filled with 3.0 $\mathrm{ml}$. of dye mixture. This defect is regarded as adequate. More satisfactory criteria are necessary, therefore, to determine when to perform a second procedure. These will be formulated only on a basis of careful study of haemodynamics and assessment of defect size in patients who appear to be unsatisfactory.

Necropsy studies of 6 of 7 infants dying early after balloon septostomy revealed adequate defects in all but one. Fig. 2a, b, and c show typical examples of these defects, in which the thin floor of the fossa ovalis has been torn across transversely from its free edge at the foramen ovale, creating defects that correspond essentially to the fossa ovalis. Fig. 2d shows the inadequate defect, with no splitting of the fossa ovalis, and associated with a much more ovoid, tough-edged fossa. In this patient the maximum balloon volume that could be pulled through the septum was I. $8 \mathrm{ml}$., and it was doubtful at the time if adequate splitting had been achieved. The pre-existing acidosis was controlled, but the baby developed heart failure and died several 

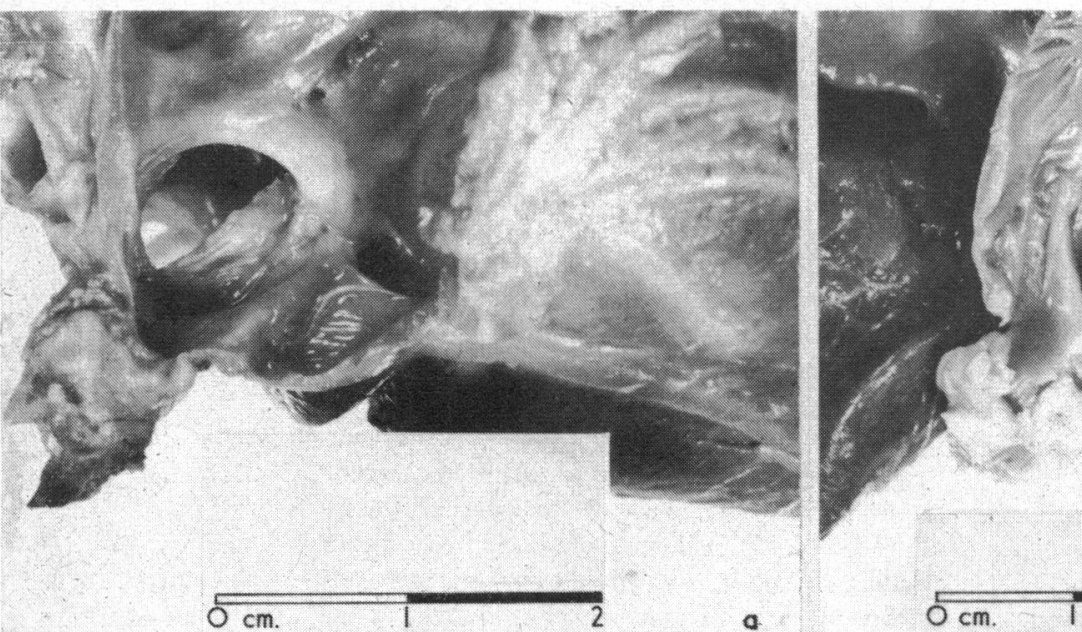

a
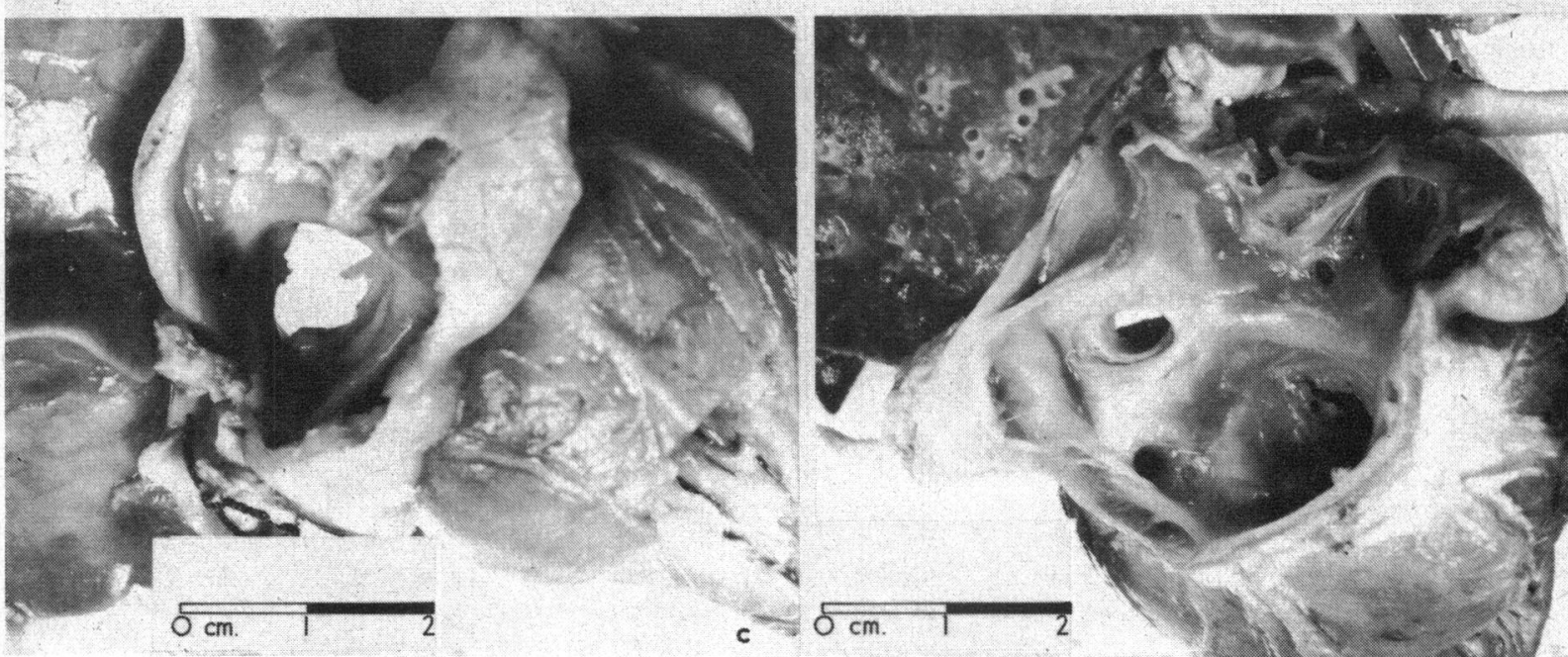

FIG. $2(a, b$, and $c)$ Atrial septal defects produced by balloon septostomy in infants with complete arterial transposition, showing tearing of floor of fossa ovalis. (d) An inadequate defect with no tearing of a much tougher fossa. Specimens viewed from right atrial aspect.

days later. In the 25 other completed procedures, the balloon volume ranged from $2 \cdot 0$ to $3.5 \mathrm{ml}$., with a mean volume of $3.0 \mathrm{ml}$. In 17 infants a balloon containing $3.0 \mathrm{ml}$. or more was withdrawn after the fossa ovalis had been split. The balloon volume was limited to $2 \cdot 0$ $\mathrm{ml}$. in 2 cases. In one, the limiting factor in passage of a larger volume was impaction of the balloon in the inferior vena cava before it had passed wholly through the atrial septum. At a later catheterization at 4 months a $3.0 \mathrm{ml}$. balloon passed through this defect easily. In the other infant the septum was felt to tear, but only $2.0 \mathrm{ml}$. could be withdrawn. That such a volume can in fact produce a defect comparable to those in Fig. 2a-c is shown by Fig. 3, which shows the defect produced in an infant with total anomalous pulmonary venous drainage by passage of a single lumen U.S. Catheter Corporation catheter containing only $2.0 \mathrm{ml}$. It should be noted that filling of the balloon of the Edwards double lumen catheter used in most of the present series beyond $2.5 \mathrm{ml}$. causes elongation of the balloon along the catheter rather than increase in its diameter. Balloon volume is a useful and reliable reference point. The Edwards double lumen catheter with a volume of $3.0 \mathrm{ml}$. of dye mixture produces a balloon diameter of approximately $15 \mathrm{~mm}$. 


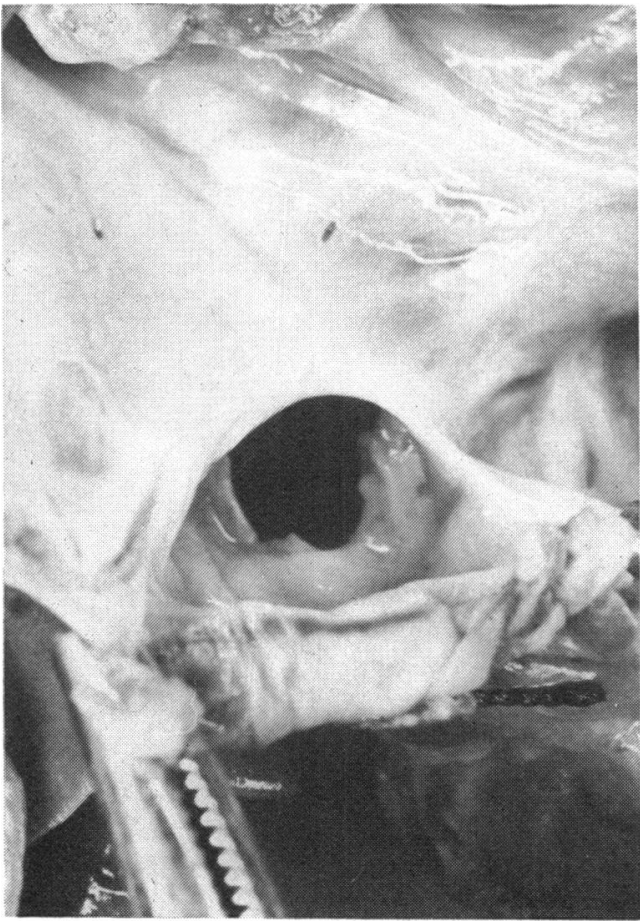

FIG. 3 Atrial septal defect produced by balloon septostomy in an infant with total anomalous pulmonary venous drainage, viewed from inferior vena cava.

Inspection of Fig. 2a-c suggests that the size of defect made by balloon septostomy is limited by the size of the fossa ovalis and its thin floor. These defects are smaller than the defects usually seen after the Blalock-Hanlon procedure. If there is no real sensation of splitting and the volume that can be withdrawn is limited, by resistance at the septum rather than other factors such as impaction in the inferior vena cava, one must expect the defect to prove inadequate. Balloon filling beyond about $2.5 \mathrm{ml}$. probably merely confirms maximum splitting rather than contributes significantly to the size of the defect.

Apparent maximum splitting does not guarantee long-term adequacy of the defect. Balloon filling ranged between 2.5 and $3.5 \mathrm{ml}$. in those infants who have required later secondary procedures to produce a larger defect. Though a proportion of cases with early adequate palliation will require secondary procedures, many will enjoy the obvious advan- tages of avoiding thoracotomy and a surgical procedure to create an atrial septal defect.

It is evident that great care is required to avoid atrial perforation. In addition to the three atrial perforations described above, a further perforation occurred during a procedure when defect size was being tested after performance of septostomy. In this infant the catheter tip failed consistently to pass into a left upper lobe pulmonary vein as usual, and finally slipped through the end of the left atrial appendage during manipulation there. There was no evidence of haemopericardium, but cardiac arrest occurred and external cardiac massage was necessary. In the experience of the unit cardiac perforation has been confined to balloon septostomy. Perforations were not noted by Rashkind (Rashkind and Miller, 1968), but one instance was recorded by Cartmill, Celermajer, and Bowdler (1967).

The author is grateful to those who have referred patients. Palliative surgical procedures were performed by Mr. G. W. Westlake and Mr. P. G. Jones. Observations on the defects seen at the time of reparative surgery in infants with total anomalous pulmonary venous drainage were made by Mr. H. D'Arcy Sutherland at the Royal Adelaide Hospital.

\section{References}

Cartmill, T. B., Celermajer, J. M., and Bowdler, J. D. (1967). Cyanotic congenital heart disease: new trends in management of transposition of the great arteries. Medical fournal of Australia, 2, 1019.

Plauth, W. H., Jr., Nadas, A. S., Bernhard, W. F., and Gross, R. E. (1968). Transposition of the great arteries; clinical and physiological observations on 74 patients treated by palliative surgery. Circulation, 37, 316.

Rashkind, W. J., and Miller, W. W. (1966). Creation of an atrial septal defect without thoracotomy; a palliative approach to complete transposition of the great arteries. Fournal of the American Medical Association, 196, 991.

-, and - (1968). Transposition of the great arteries; results of palliation by balloon atrioseptostomy in thirty-one infants. Circulation, 38, 453.

Venables, A. W. (1966). Complete transposition of the great vessels in infancy with reference to palliative surgery. British Heart fournal, 28, 335.

(I968). Creation of atrial septal defects by the balloon catheter technique in infants with complete transposition of the great vessels. Australian Paediatric fournal, 4, 236.

Watson, H., and Rashkind, W. J. (1967). Creation of atrial septal defects by balloon catheter in babies with transposition of the great arteries. Lancet, $\mathbf{I}$ 403. 